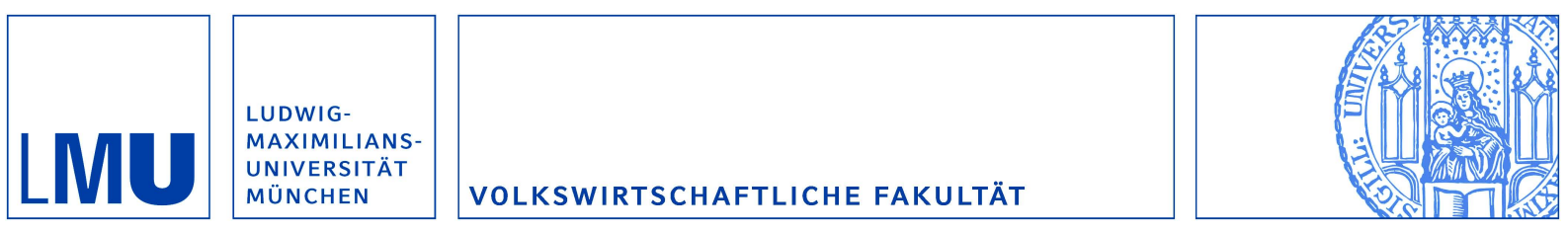

Vetter, Stefan; Heiss, Florian; McFadden, Daniel und Winter, Joachim:

Risk attitudes and Medicare Part D enrollment decisions

Munich Discussion Paper No. 2012-8

Department of Economics

University of Munich

Volkswirtschaftliche Fakultät

Ludwig-Maximilians-Universität München

Online at https://doi.org/10.5282/ubm/epub. 12740 


\title{
Risk attitudes and Medicare Part D enrollment decisions
}

\author{
Stefan Vetter \\ University of Munich \\ Florian Heiss \\ University of Mainz \\ Daniel McFadden \\ University of California, Berkeley \\ University of Southern California, Los Angeles \\ Joachim Winter \\ University of Munich
}

This version: February 5, 2012

\begin{abstract}
The new Medicare Part D program provides prescription drug coverage for older Americans through highly subsidized and tightly regulated plans offered by private insurance firms. For most eligible individuals without coverage from other sources, obtaining Part D coverage would be rational, but it requires active enrollment and plan choice decisions. We investigate if non-enrollment in Medicare Part D can partly be explained by risk aversion. Data are taken from a national online survey conducted just after the introduction Part D. The survey included a context-free and a context-related hypothetical lottery to measure an individual's attitude towards risk. Respondents who are risk tolerant according to these measures were significantly less likely to enroll in Part D. We also illustrate that hypothetical choice questions designed to elicit risk attitudes are subject to reference-point effects. Even minor differences in the priming of respondents can result in potentially misleading conclusions about the role of risk aversion in the insurance decisions.
\end{abstract}

Keywords: Risk aversion, Medicare Part D, heterogeneous preferences, insurance demand, survey design

JEL classification: D03, D81, H51, I1

We would like to thank Helmut Farbmacher, Iris Kesternich, Ulrich Schmidt and seminar participants at the IfW Kiel, the University of Munich, and ICES at George Mason University for valuable comments and suggestions. This research was supported by the Behavioral and Social Research program of the National Institute on Aging (grants P01 AG 05842-18, R56 AG026622-01A1, and 1RC4AG039036), with additional support from the E. Morris Cox Fund at the University of California, Berkeley, and by MC Health at the University of Munich. 


\section{Introduction}

Risk preferences are crucial for understanding individual choices whenever agents make economic decisions under uncertainty. Consequently, the demand for insurance coverage as a means of reducing or eliminating uncertainty depends on the individual attitude to risk. Standard economic theory predicts that risk averse individuals will always opt for insurance when it is actuarially fair, and will generally have more insurance coverage than risk seeking agents. This paper studies the link between risk aversion and medical insurance coverage in the context of Medicare Part D, which was introduced in the United States in the beginning of 2006. It offers insurance coverage against "catastrophic" costs for prescription drugs and is targeted to Americans aged 65 and older.

Since the main objective of Medicare Part D is to reduce the number of persons without health insurance coverage, the program is generously subsidized so that the vast majority of the eligible population unequivocally benefits from it. However, for individuals with currently low expenses for pharmaceutical drugs it may be optimal not to enroll if they expect their drug bill to remain low for the near future. Here is where risk aversion comes into play. Future expenses for pharmaceutical drugs are uncertain and current expenses or health status are only imperfect indicators for the future (e.g., Winter et al., 2006; Heiss et al., 2010). This is especially true for people around retirement age, whose health status is likely to decline over time. One might therefore expect that highly risk averse persons choose to enroll even when they are still in relatively good health. On the other hand, individuals who perceive the risk of catastrophic drug costs to be tolerably small may decide to defer enrollment in Medicare Part D to a future date and remain uncovered for the moment.

Medicare Part D provides an excellent opportunity to study if this self-selection process is actually at work. ${ }^{1}$ In 2006, the Part D standard plan, as formulated by the Centers for Medicare and Medicaid Services, had an annual premium of $\$ 444$ and a deductible of $\$ 250$. For prescription drug costs of up to $\$ 2,250$ it pays $75 \%$ of the pharmacy bill. Between $\$ 2,250$ and $\$ 5,100$ there is a "donut hole" without additional benefits, but the standard plan covers $95 \%$ of the costs above $\$ 5,100$. With these features, the break-even point for enrollment in 2006 was prescription drug costs of $\$ 842$. Winter et al. (2006) calculate that only $27 \%$ of the Medicare-eligible population fell below this level. However, because of a late enrollment penalty (a 1\% increase in premium for each month of delay), enrollment was dynamically efficient even for many with a slightly lower bill. Non-enrollment was only optimal for

\footnotetext{
${ }^{1}$ A series of papers investigates enrollment decisions and plan choice in Medicare Part D, but as Ketchman et al. (2011) note, little is known about the role of risk attitudes in decisions on Part D enrollment and plan choice. We review the existing literature on Part $\mathrm{D}$ in more detail below.
} 
currently healthy individuals who expected expenses for prescription drugs to remain low in the near future. Many Americans in the target population did not have to make an active decision because they had prescription drug coverage via their employer, which was automatically converted to Part D coverage. Only those who did not fall into this category had to make a choice of whether to enroll or not. We will refer to these persons as "active deciders". An overview of the institutional features of Part D is provided for example in Winter et al. (2006), Duggan et al. (2008), or Duggan and Scott Morton (2010).

For our purposes, a particularly attractive feature of the design of Part D is the late enrollment penalty, which ensures that hardly anybody should find it optimal not to enroll in the inaugural period only to obtain Part D coverage shortly afterwards. Therefore, almost everybody who decided not to enroll during the first six months must have done it with the expectation of remaining uncovered at least until the next official enrollment period. Furthermore, since enrollment in a Part D plan was strictly optimal for drug costs exceeding $\$ 842$ per year it should largely be independent of income or wealth - quantities for which it is usually difficult to obtain reliable information in surveys.

In our paper we focus on the role of risk aversion in the decision of whether to sign up for Medicare Part D. The determinants of enrollment in Part D have been examined by Heiss et al. (2007) and Levy and Weir (2010). The former study used the RPS, while the latter employed the Health and Retirement Study (HRS) which is larger and contains more background variables than the RPS, but is less detailed with respect to information related to Part D. Both studies find that current prescription drug use is the most important determinant for enrollment. In addition, respondents with poor or very poor self-assessed health are more likely to enroll. Levy and Weir also show that enrollment is positively related to a proxy for IQ. Apart from that, the take-up decision seems to be unrelated to most other background variables, in particular variables reflecting educational attainment, income and wealth. ${ }^{2}$

In the analysis of insurance decisions, the role of individual heterogeneity in preferences, for example risk aversion, has so far often been neglected. As Finkelstein commented, "an important direction for future work - both for Medicare Part D and for other social insurance programs more generally - is distinguishing between 'true' preference heterogeneity and failures of rationality" (Finkelstein, 2010). If differences in risk preferences

\footnotetext{
${ }^{2}$ A series of recent papers studies individuals' plan choice conditional on enrollment (Abaluck and Gruber, 2011a,b; Ketcham et al., 2011; Kling et al., 2011; Heiss et al., 2012). Depending on the region where they live, individuals who have decided to enroll can choose among around 40 different plans that differ various dimensions, such as premium, copay and coinsurance regulations, and coverage in Part D's infamous "donut hole". These papers generally show that plan choices are far from optimal but the assessment of how large this problem is varies across these studies.
} 
can partly explain enrollment choices, this also has important implications for the benefits of allowing individuals to choose within social insurance. As there is also individual heterogeneity in risk perceptions, these need to be separated from risk aversion (Spinnewijn, 2009). In the survey from which our data are taken, risk preferences were elicited by means of hypothetical lotteries with an objectively quantifiable risk in order to eliminate differences in perceptions.

The introduction of Part D was accompanied by the launch of the Retirement Perspectives Survey (RPS) which surveyed a large sample of older Americans immediately before the initial enrollment period started on November 15, 2005. ${ }^{3}$ The survey participants were re-interviewed shortly after the initial enrollment period ended on May 15, 2006. The RPS contains two questions which are intended to reflect an individual's attitude towards risk. One is a standard "textbook" lottery with a 50:50 chance of winning a monetary price, which elicits the respondents' willingness-to-accept (WTA) for such a lottery. The other question elicits willingness-to-pay (WTP) for a hypothetical insurance against a 5\% shortfall risk. These questions account for the different behavior of people in the gain and loss domain (Kahneman and Tversky, 1979). Our main substantive finding is that those respondents who are risk tolerant according to these measures were significantly less likely to enroll in Part D.

An important survey design question is whether a general measure of risk aversion has higher predictive power than a context-specific measure. Our results confirm previous research which finds that context-specific measures are superior when employed in the context at hand. A special feature of the RPS which we also exploit is that both risk preference measures were asked in two ways: first in a bracketed format and afterwards as an open-ended question. Since the sample was randomly split by half into different bracketing conditions for both questions, this two-step procedure allows us to explore whether differential priming leads to the emergence of different reference points. When considering risk aversion as a potential predictor for enrollment into Medicare Part D we find that even minor differences in the priming of respondents would lead to different conclusions.

The paper is organized in the following way: in Section 2 we discuss related literature about the association between risk attitudes and behaviors in the health domain. Section 3 presents the relevant section of the questionnaire. In Section 4 we explain our risk measures and present an overview of descriptive results and framing effects. In Section 5 we apply the risk preference questions to Medicare Part D enrollment, and Section 6 concludes.

\footnotetext{
${ }^{3}$ https://www.cms.gov/MedicarePresDrugEligEnrol/Downloads/PDPEnrollmentGuidanceUpdateFINAL2010.pdf
} 


\section{Measures of risk preferences and health behavior}

While the evolution of a person's health status over time is highly uncertain, individual behavior can have a considerable impact upon its expected path. Economists have been investigating if an individual's aversion to risk is actually reflected in a tendency to engage in risk reducing activities (e.g. preventive medical checks) or avoiding risk enhancing behaviors (e.g. smoking, heavy drinking, or consuming unhealthy food). Anderson and Mellor (2009) conduct a large-scale experiment to examine the association between risk attitudes and risky health behaviors, and show that smoking, heavy drinking, and obesity are significantly less prevalent among risk averse persons. They elicit risk attitudes using the procedure of Holt and Laury (2002). ${ }^{4}$ Picone et al. (2004) use data from the HRS and find no significant correlation between risk aversion and the demand for preventive medical tests. Their measure of risk aversion is the willingness to engage in hypothetical gambles about lifetime labor income.

Dohmen et al. (2010) investigate how a self-assessed measure for risk attitudes predicts risk taking in different domains. They use data from the German Socioeconomic Panel (SOEP) in which respondents rated their willingness to take risks in general and in specific domains, such as financial investments and health, on a scale from 1 to 10 . The willingness to take risks in general, and even more so the willingness to take health risks, is positively and significantly correlated with smoking, while self-reported risk taking in other domains has less predictive power. Heiss et al. (2011) included self-assessed risk attitude measures based in these SOEP questions in a predictive regression model for Part D enrolment (using the same dataset we analyze in the present paper) and found no significant effect.

Related to the question of whether risk attitude is a general character trait or varies across domains is the study of van der Pol and Ruggeri (2008) who investigate whether an individual's risk attitude in hypothetical gambles for life years differs from the risk attitude in quality of life gambles. They find that individuals tend to be risk averse with respect to the gamble involving risk of immediate death, but risk seeking with respect to other health gambles.

The relationship between risk aversion and health insurance coverage was examined by Barsky et al. (1997) and Giuso and Paiella (2006). Barsky et al. show that the probability of being covered by health insurance or life insurance increases with the respondents' aversion to risk as measured by the hypothetical income gambles in the HRS. In contrast, Guiso and Paiella (2006) obtain the finding that risk averse individuals are significantly less likely to have

\footnotetext{
${ }^{4}$ For the use in sample surveys, this procedure might be less well suited since it requires more time than what is usually available.
} 
health insurance coverage. However, their measure of risk aversion is a question about the willingness-to-pay for a hypothetical risky asset from the Italian Survey of Household Income and Wealth, which has several problems. The framing in an investment context probably explains the excessive proportion of risk averse choices (96\%). Only 3.6\% of answers indicated risk neutrality, and only $0.55 \%$ reflected risk tolerance, which is unreasonably low even in financial contexts. Furthermore, while this risk preference measure can explain portfolio composition it probably does not accurately reflect risk aversion in non-financial contexts. Finally, many respondents perceived the question as too difficult and refused to answer. None of these problems arises with the two risk preference measures in the Retirement Perspectives Survey, which will be described in the next section.

\section{The Retirement Perspectives Survey}

We use data from the Retirement Perspectives Survey which was specifically designed to study the introduction of Medicare Part D in 2006. The RPS was conducted in four waves in 2005, 2006, 2007 and 2009 by Knowledge Networks, a commercial survey firm which administers a large panel of households. Panel members are representative for the U.S. population in terms of demographic and socioeconomic characteristics. They are periodically surveyed via a web TV hardware device and receive financial rewards for their participation. The objective of the RPS was to collect information about the responsiveness of older Americans to the introduction of the new Medicare Part D program during the first months of 2006, their plan choices and their experiences with the program. Heiss et al. (2007) provide a detailed description of the RPS. The analysis below uses data from the first two waves with 2598 observations. Respondents were between 50 and 97 years of age at the beginning of the survey.

In addition to questions about Medicare Part D, health conditions and sociodemographic status, the RPS also contains a section on risk preferences. It includes two hypothetical lotteries which differ not only in probabilities and expected payoffs, but also in the context. In addition, one lottery is framed in terms of a potential gain, while the other is about a potential loss. This accounts for the markedly different behavior in situation involving gains and losses (Kahneman and Tversky, 1979). In order to investigate potential bracketing effects, the sample is split in half and each half received different brackets for each lottery. The relevant section of the questionnaire can be found in Appendix A. 
In each of the two risk preference questions the respondents had to indicate which certain amount would leave them indifferent with the risky lottery. The main virtue of question A1, the first measure of risk preference, is its simplicity. Participants were asked:

"Suppose your supermarket announces that in a drawing from its customers you are the winner of the grand prize. This prize gives you a fifty-fifty chance of getting $\$ 10,000$ or getting nothing. Alternately, you may choose an amount for certain rather than taking a chance of getting nothing.

Please indicate for each of these amounts whether you would take it for certain (rather than taking a fifty-fifty chance of getting \$10,000 or nothing): "

In question A1 a decreasing sequence of dollar amounts was presented and respondents had to decide for each amount if they preferred to accept this amount instead of playing the lottery. In addition, respondents were randomly assigned to one of two conditions. The wide brackets treatment presented a wider range of alternative dollar amounts $(\$ 6,500, \$ 5,000$, $\$ 3,500, \$ 2,000$ ), while the alternatives in the other treatment covered a narrower range (with amounts $\$ 6,000, \$ 5,500, \$ 5,000$, and $\$ 4,500$ ). Clearly, a person who accepts $\$ 6,500$ dollars instead of playing the lottery but prefers the lottery for lower amounts is less risk averse than another person who finds a certain amount of $\$ 5,000$ still better than taking a risk and playing the lottery.

In order to have a comparable measure across treatments and to fully account for individual heterogeneity, participants then had to answer the same question in an open-ended format (question A2), i.e. they had to state the minimum amount which would just be sufficient to forego the lottery. The answer to this open-ended question will serve as our first risk preference measure. The expected value of $\$ 5,000$ corresponds to risk neutrality, while a WTA below (above) \$5,000 indicates risk aversion (tolerance). The payoffs and probabilities in this hypothetical lottery are easy to understand, and even people without a sophisticated mathematical background should intuitively grasp that the lottery pays $\$ 5,000$ in expectation. Another feature of question A2 is that it is basically context-free.

In contrast, the second risk measure B1 is explicitly framed in an insurance context, although not health-related but as an insurance against the cancellation of a holiday trip: 
"Suppose you are planning a vacation that costs $\$ 2,000$ up front. There is a five percent chance that something will come up, and you will be unable to go. Your travel agent offers you insurance that will refund your $\$ 2,000$ if you can't go.

Please indicate below whether you would buy this insurance at various costs rather than taking a chance: “

Respondents were again assigned to two bracketing treatments. The first offered a wider range $(\$ 40, \$ 70, \$ 100, \$ 130)$ while the amounts in the second sequence $(\$ 85, \$ 100$, $\$ 115, \$ 130)$ were narrowly centered around the expected value of $\$ 100$. Then the same hypothetical situation was again presented as an open-ended question (B2), which provides the second measure for risk preference. Each respondent had to report her maximum willingnessto-pay for this insurance, and higher values represent an increasing aversion against risk.

From a survey design perspective, a potentially useful feature of this two-step procedure is that it helps respondents to understand the questions by providing anchors. This probably explains why the nonresponse rate is extremely low (around 2.2\% for A2 and 2.0\% for B2). ${ }^{5}$ Other elicitation procedures, such as those used in Barsky et al. (1997) or Holt and Laury (2002), indicate a range for a respondent's coefficient of risk aversion. While Kimball et al. (2008) demonstrate that one can construct a cardinal proxy from these ordinal risk aversion measures, explicitly taking measurement error into account, their procedure requires repeated observations and assumptions such as risk aversion being constant over time. Instead, the RPS questions directly provide a point estimate for risk attitudes. The answers to these questions are obviously subject to noise, but as measurement error would most likely lead to attenuated coefficients in our setting, the results presented in the last section can be interpreted as conservative estimates of the link between risk aversion and Part D enrollment.

While several studies, for example Dohmen et al. (2009), suggest that a context-specific measure for risk attitude has more predictive power for actual behavior than general measures, some respondents might find the amounts and probabilities involved in B2 more difficult to process than those in A2. It is therefore difficult to form an a-priori conjecture about the relative predictive power of both questions. It turns out, however, that B2 contains more information than A2.

\footnotetext{
${ }^{5}$ In comparison, the question employed by Guiso and Paiella (2006) was answered by only 3458 out of 8135 respondents (or 42.5\%). The remaining persons either reported "don't know", or refused to answer or pay a positive price for a hypothetical risky asset.
} 


\section{Construction and properties of the risk measures}

\subsection{A framework consistent with Prospect Theory}

Prospect theory (Kahneman and Tversky, 1979) is the descriptively most successful alternative to expected utility theory. One of the key predictions of prospect theory is that individuals behave risk averse with respect to potential gains, but risk seeking in situations which involve a potential loss. As we will show in the next section, the risk preference questions in the RPS reveal a picture which is consistent with this theory. Respondents are generally risk averse or risk neutral in the supermarket lottery, but mainly risk seeking in the question about the hypothetical travel insurance. We use the following CRRA two-part power function proposed by Tversky and Kahneman (1992) to calculate risk aversion coefficients separately for the gain and loss domain:

$$
v(x)=\left\{\begin{array}{l}
x^{\alpha} \text { if } x \geq 0 \\
-\lambda(-x)^{\beta} \text { if } x<0
\end{array}\right.
$$

where $\mathrm{x}$ represents the potential gain or loss, and $\alpha$ and $\beta$ are the corresponding risk aversion coefficients for lotteries involving gains and losses, respectively. By $\lambda$ we denote the coefficient of loss aversion, which specifies by how much more individuals suffer from a loss than they would benefit from an equally large gain. ${ }^{6}$

We calculate the coefficient $\alpha$ for $A 2$ and $\beta$ for B2. We do this by setting the expected utility of the lottery equal to the respondents' reported certainty equivalent (the answers in A2 and B2). By doing this, $\lambda$ cancels out and we can solve numerically for $\alpha$ or $\beta .^{7}$

To ensure that our functional form assumption is not too restrictive, we perform a functional form test with our specifications estimated in section 5. We add restricted cubic splines of the original answers (Stata module "rc_spline" by Dupont and Plummer) but find no evidence that a different functional specification would be preferable.

\footnotetext{
${ }^{6}$ Tversky and Kahneman (1992) estimate $\lambda$ to be around 2.25.

${ }^{7}$ Calculating risk aversion coefficients instead of using raw answers offers the advantage of reducing the effect of outliers but entails two minor complications. First, the power utility specification results in a very high $\alpha$ for a WTA above $\$ 9,000$, and a very high $\beta$ for a WTP above $\$ 1,000$. To avoid extreme outliers, we top-code $\alpha$ and use the same coefficient as for $\$ 9,000$ also for the very few even higher answers (1 person with $\$ 9,500$ and 13 with $\$ 9,999)$. In the same way, we use the $\beta$ corresponding to $\$ 1,000$ also for three outliers ( 1 person each with $\$ 1,500$, $\$ 1,800$ and $\$ 1,900$ ), and drop respondents whose stated WTP is above $\$ 2,000$, i.e. higher than the value of the trip itself. The second complication is that $\alpha$ and $\beta$ are not defined for 0 . We therefore use the same coefficient as for the lowest positive amount ( $\$ 1$ in both cases) also for $\$ 0$ answers. We performed several robustness checks with alternative cutoff points and obtained very similar results.
} 


\subsection{Descriptive statistics}

Before we will restrict our analysis of the Part D take-up decision in section 5 to active deciders, the descriptive results for the risk aversion questions and the framing effects in this section are reported for the entire sample.

Figure 1 shows the distribution of answers to question A2. A few aspects are worth pointing out. Firstly, the majority of respondents make a risk averse choice. Around one quarter of answers indicate risk neutrality and only $11.8 \%$ in our sample are risk seeking and state a WTA of more than $\$ 5,000$. Secondly, the expected value of the lottery is by far the most frequent answer. Furthermore, multiples of 1000 and 500 are focal points which attract the bulk of answers, especially when they were included in one of the bracketing treatments.

In the open-ended question, all amounts between $\$ 1$ and $\$ 9,999$ are not unreasonable apriori. While indeed nobody stated a higher value, there is a nontrivial number of $\$ 0$ answers (77 respondents, or 3.1\%). Since a rational decision maker would not prefer a certain amount of $\$ 0$ to a 50:50 chance of either winning a positive amount or getting nothing, it might be tempting to interpret $\$ 0$ answers as reflecting a WTA very close to zero and correspondingly a very high degree of risk aversion. However, these answers could also be motivated by an aversion against such gambles in general. The problem of correctly interpreting these ambiguous answers is inherent in this type of lotteries and has also been encountered by Hartog et al. (2002), for example. However, we can employ our two-step procedure to shed more light on this issue. The vast majority of those with a $\$ 0$ answer rejected all possible amounts in the preceding question, thereby indicating extreme risk aversion in the open-ended question, but a very high degree of risk tolerance in the bracketed question. This inconsistent pattern makes these answers highly suspicious and presumably expresses a general aversion against engaging in gambles of this type, rather than accurately reflecting an individual's attitude in risky financial decisions. While we do not drop these answers for our analysis of the determinants of Part D enrollment in Section 5, our main findings do not change when we exclude these suspicious answers. ${ }^{8}$

In $\mathrm{B} 2$ again the risk neutral choice, in this case $\$ 100$, was the most frequent answer. Figure 2 shows the distribution which is truncated at 200 for expositional clarity. While many respondents rounded to multiples of 50, also the amounts previously seen in the bracketed questions $(\$ 40, \$ 70, \$ 85, \$ 130)$ were frequently chosen. The majority of answers $(54 \%)$ fall into the risk seeking region, which is consistent with prospect theory. However, the high

\footnotetext{
${ }^{8}$ Results are available upon request.
} 
proportion of risk tolerant subjects is an interesting result in the light of previous studies which found that framing a question in an insurance context enhances risk averse choices (see for example Hershey et al. 1982, or Wakker et al., 2007).

Those respondents who reported a WTP of \$0 in B2 were overwhelmingly consistent in the sense that they had also opted for a risk seeking choice in B1. Unlike in A2, there is therefore no reason to find $\$ 0$ answers generally suspicious, and they can be interpreted as WTP very close to zero (presumably everybody would buy this insurance for 1 cent). However, there are some problematic answers on the other end of the scale which correspond to an implausibly high degree of risk aversion (for some people the reported WTP for the travel insurance was even higher than the hypothetical value of the trip itself). Again a comparison of the closed and open-ended questions can help to assess the reliability of answers. Most respondents who stated an amount between $\$ 500$ and $\$ 2000$ (1.57\% in our sample) were by far less risk averse in the preceding bracketing question, which suggests that these outliers reflect a misunderstanding of the question rather than extremely high risk aversion.

\subsection{Framing effects}

In order to assess whether the two bracketing conditions in A1 affect response behavior it is instructive to compare the proportion of rejections at the only amount included in both treatments, which is the lottery's expected value of $\$ 5,000$. Table 1 shows that $14.96 \%$ of the respondents in the "wide" brackets group rejected a certain payment of $\$ 5,000$ in favor of playing the lottery, compared to $18.14 \%$ in the "narrow" brackets group. While this difference is small, the answers to the following open-ended question A2 show that the priming was not without effect. The median answer in the wide brackets treatment was $\$ 2500$, compared to $\$ 3500$ in the narrow brackets treatment (the mean was $\$ 2920$ and $\$ 3202$, respectively). A Kolmogorov-Smirnov test clearly rejects the hypothesis that both samples are drawn from the same distribution ( $\mathrm{p}$-value $=0.000)$.

Preceding A2 by the bracketing treatments introduces different reference points which affect the answers to the open-ended question. Figure 3 shows that while both framings exhibit large spikes at $\$ 5,000$ and $\$ 1,000$, many respondents chose one of the numbers previously seen in A1. 46 persons $(20.8 \%)$ in the wide brackets treatment stated either $\$ 6,500, \$ 3,500$ or $\$ 2,000$ in $\mathrm{A} 2$, compared to only 12 persons (or 5.6\%) in the narrow brackets treatment. Conversely, the reference points which only respondents of the narrow brackets treatment were exposed to were $\$ 6,000, \$ 5,500$, and $\$ 4,500.30$ respondents $(14.2 \%)$ in this group stated one of these amounts in A2, but only 7 persons (or 3.2\%) did so in the wide brackets treatment. The 
cumulative distribution functions in Figure 4 demonstrate that there are some bracketinginduced differences, especially at $\$ 2,000$ and $\$ 6,000$, but also at $\$ 6,500$. However, bracketing effects are confined to the region between $\$ 2,000$ and $\$ 6,500$. The fraction and distribution of answers below or above this range are almost identical.

With respect to $\mathrm{B} 2$, even casual inspection shows that the treatment effect is more pronounced (see Figure 5). The fact that they saw the $\$ 85$ option in B1 induces 132 persons (or $10.54 \%$ ) of those in the narrow brackets condition to report exactly this number in B2. Another 21 (or $1.68 \%$ ) adopted the previously seen $\$ 115$. In the wide treatment, both numbers were stated not even once. Conversely, 270 persons in the wide treatment named either $\$ 40$ or $\$ 70$ in $\mathrm{B} 2$, which amounts to more than $21 \%$. In the other framing, only $0.8 \%$ chose these numbers. Both bracketing treatments included the expected value of $\$ 100$ as a cut-off point, but while 49.83\% would have bought the hypothetical travel insurance for this price in the narrow brackets treatment, only $39.27 \%$ would have done so in the wide condition (see Table 1). The inclusion of cheap alternatives ( $\$ 40$ and $\$ 70$ ) clearly changes the respondents' valuation of the insurance. Interestingly, there is almost no difference with respect to the fraction of answers above and below $\$ 130$, which is the second value common to both treatments. However, the cumulative distribution function (Figure 6) reveals that bracketing-induced distortions are not confined to the area between 40 and 130, but rather affect the entire distribution. Those persons who were assigned to the narrow brackets treatment, with $\$ 85$ as the lowest suggested value, are more likely to have a WTP below \$40. The framing effect is strongest in between 40 and 100 , but there remains a difference even above 130. The treatment effect is reflected in the median answers to B2. While the respondents assigned to the narrow brackets state a median willingness-to-pay of $\$ 100$, those in the wide brackets treatment are significantly more riskloving, with a median of $\$ 70$. Again, a Kolmogorov-Smirnov test rejects that both samples are drawn from the same distribution ( $\mathrm{p}$-value $<0.001)$.

\subsection{Determinants of the measures for risk attitude in the RPS}

Our objective in this section is twofold. First, we want to examine whether there remains a significant treatment effect when we control for covariates which have been found to be associated with risk attitudes in other studies based on different datasets. Second, we are interested in whether there is a correlation between some socio-demographic covariates and the answers to the lottery questions.

As shown in Table 2, the bracketing-induced treatment effects are also evident when we regress the risk preference measures (both the raw answers and the calculated risk aversion 
coefficients) on socio-demographic variables. In all regressions the treatment dummy is highly significant ( $\mathrm{p}$-value $<0.001)$.

Two further conclusions emerge from Table 2: First, converting the raw answers into the risk aversion coefficients $\alpha$ and $\beta$ does not substantially alter the results. Second, the association between the risk preference measures and respondent characteristics is low, especially in the case of A2. This contrast with Dohmen et al. (2005) and Hartog et al. (2002), for example, who show that women are significantly more risk averse, and that risk aversion increases with age and a measure of subjective health status, while a better education level is associated with higher risk tolerance. Both papers also report some evidence for a positive relationship between income and risk tolerance. Halek and Eisenhauer (2001) as well as Donkers et al. (2001) find similar effects for gender and education. ${ }^{9}$ Generally we find little association between reported certainty equivalents and demographic characteristics. Columns (3) and (4) show that B2 is significantly lower for persons with education below high school level and significantly higher for nonwhite respondents, and that poor or very poor selfreported health is associated with slightly more risk averse choices. There are no significant differences across household income levels, but the income measure in the RPS is self-reported and neither informative about the source of income (e.g. labor income vs. pension income), nor about the relative contribution of the household members to the total household income or about how much is actually disposable. In contrast to the previously mentioned studies we do not find a gender effect. However, Schubert et al. (1999) also employ insurance-context lotteries to measure risk aversion in the loss domain and do not find a significant gender difference.

Overall, the fact that A2 is not significantly associated with any of the respondents' characteristics might be indicative that it is a noisier measure than B2. On the other hand, both risk aversion measures might measure different aspects of risk aversion, which cannot be explained in the same fashion. Interestingly, within respondents $\alpha$ and $\beta$ are virtually unrelated, with a correlation coefficient of $-0.0161(p-v a l u e=0.4207)$.

\section{Risk aversion as a predictor of enrollment in Medicare Part D}

Out of the 2598 respondents in our sample, 443 are active deciders and had to make a decision. 349 of them enrolled in a Part D plan, while 94 remained uncovered. Since the RPS was

\footnotetext{
${ }^{9}$ Surveys of evidence for gender differences in risk taking can be found in Eckel and Grossman (2008), and Croson and Gneezy (2009).
} 
targeted at older Americans, respondents were explicitly asked if a family member decided for them. Those 21 persons who reported that someone else took the decision on their behalf were consequently excluded. ${ }^{10}$ We also dropped 15 respondents with missing answers or a WTP for B2 of $\$ 2000$ or higher.

In order to uncover the role of risk aversion in the Part D enrollment process we estimate probit models in which we regress the enrollment decision of the active deciders on our measures of risk attitudes and a set of covariates. We correct for potential bracketing effects in the elicitation procedure by including a treatment dummy in each regression. As a measure for the demand of prescription drugs we use expenditures for 9 frequent symptoms, calculated by Winter et al. (2007). The regressions further includes dummy variables for having been covered by a different type of medical insurance before the introduction of Part $\mathrm{D}$, age (older than 75 years), low educational attainment (less than highschool), sex, income (dummies for reported income below $\$ 30,000$ or above $\$ 60,000$ ), ethnicity, and excellent and poor/very poor self-reported health.

Table 3 presents our estimation results. Column (1) contains the coefficients of a baseline specification without our risk aversion measures. Not surprisingly, current expenses for prescription drugs are an important determinant for enrollment. We also find that respondents who previously had prescription drug coverage which was not equivalent to Part D coverage were more likely to enroll, which probably reflects a substitution of their previous insurance coverage towards the subsidized program. As expected, persons with excellent selfreported health were more likely to remain uncovered. Socio-demographic factors such as age, income, education, gender and ethnic background are all insignificant, which is in line with Heiss et al. (2007) and Levy and Weir (2010).

Columns (2) and (3) contain estimates for the full sample of active deciders using either of the two measures for risk preferences individually, and the regression in column (4) uses both measures jointly. While $\alpha$ has no significant influence on the probability of enrolling, $\beta$ is highly significant. This holds regardless if $\beta$ is used individually or jointly with $\alpha$. Individuals with a higher WTP for the hypothetical travel insurance are significantly more likely to obtain Part D coverage. This result confirms that risk aversion is indeed an important determinant for enrollment in Part D. ${ }^{11}$

A comparison of columns (3), (5) and (6) sheds more light on the effects of different bracketing treatments. Across all active deciders (column 3) $\beta$ is a highly significant predictor

\footnotetext{
${ }^{10}$ All of them actually enrolled.

${ }^{11}$ As already mentioned in section 4.1 we tested whether a more flexible functional form would be more appropriate for the risk aversion measures, but find no evidence which rejects our functional form assumption.
} 
for enrollment ( $\mathrm{p}$-value $=0.005$ ). Interestingly, this result is almost entirely driven by the wide bracketing treatment (column 6); the coefficient in the narrow treatment is much smaller and far from being significant ( $\mathrm{p}$-value $=0.301$ ). We also tested whether this result could be driven by a different composition of both subsamples, but find no evidence for a failure of randomization. Apart from $\beta$, there is no variable for which can reject the hypothesis of identical distributions across treatments. The only exception is the proportion of respondents who had a different kind of medical insurance before the introduction of Part D ( $p$-value=0.03). Thus, our treatment effect is not driven by non-random assignment.

\section{Conclusion}

To the best of our knowledge, this is the first paper which focuses on the role of risk aversion in the take-up process for Medicare Part D. We find that risk attitude for losses can explain why eligible persons decided not to enroll in Part D. Using the WTP for a hypothetical insurance from a non-health context we can show that risk tolerant respondents are indeed highly significantly less likely to obtain Part D coverage. Our analysis shows that together with low current prescription drug costs and excellent self-reported health status - two variables which directly reflect limited expected financial benefits associated with Part D - risk tolerance is the most important determinant for explaining why respondents decided to remain uncovered. Our analysis also shows that risk aversion is by far more important than sociodemographic characteristics to explain non-enrollment in Medicare Part D. These findings underscore the importance of heterogeneity of risk attitudes in the analysis of insurance markets, as argued by, inter alia, Finkelstein (2010) and Spinnewijn (2009).

From a survey design perspective, this paper suggests a two-step procedure which provides anchoring values and in a first step, and fully exploits individual heterogeneity in the second step. Doing this achieves the goal of a very low non-response rate and enables us to perform consistency checks for questionable answers by comparing the responses from the open-ended and the bracket format. Whether such a two-step procedure is an efficient way to increases response rates and response quality in the context of a time-constrained internet survey, and how it compares to the same measure elicited in one step, is a question which merits further research. 


\section{References}

Abaluck, J. T. and J. Gruber (2011a): "Heterogeneity in Choice Inconsistencies among the Elderly: Evidence from Prescription Drug Plan Choice." American Economic Review, Papers and Proceedings, 101, 377-381.

Abaluck, J. T. and J. Gruber (2011b): “Choice Inconsistencies among the Elderly: Evidence from Plan Choice in the Medicare Part D Program." American Economic Review, 101, $1180-1210$

Anderson, L. R., and J. M. Mellor (2008): "Predicting Health Behaviors with an Experimental Measure of Risk Preference." Journal of Health Economics, 27, 12601274.

Barsky, R. B., F. T. Juster, M. S. Kimball, and M. D. Shapiro (1997): "Preference Parameters and Behavioral Heterogeneity: An Experimental Approach in the Health and Retirement Study." Quarterly Journal of Economics, 112(2), 537-579.

Croson, R., and U. Gneezy (2009): “Gender Differences in Risk Taking.” Journal of Economic Literature, 47(2), 1-27.

Dohmen, T., A. Falk, D. Huffman, U. Sunde, J. Schupp, and G. G. Wagner (2011): "Individual Risk Attitudes: Measurement, Determinants and Behavioral Consequences." Journal of the European Economic Association, forthcoming.

Donkers, B., B. Melenberg, and A. Van Soest (2001): "Estimating Risk Attitudes using Lotteries: A Large Sample Approach.” The Journal of Risk and Uncertainty, 22(2), 165-195.

Duggan, M., P. Healy, and F. Scott Morton (2008): "Providing Prescription Drug Coverage to the Elderly: America's Experiment with Medicare Part D.” Journal of Economic Perspectives, 22(4), 69-92.

Duggan, M., and F. Scott Morton (2010): “The Effect of Medicare Part D on Pharmaceutical Prices and Utilization." American Economic Review, 100(1), 590-607.

Eckel, C. C., and P. J. Grossman (2008): "Men, Women, and Risk Aversion: Experimental Evidence." Handbook of Experimental Economics Results, Vol. 1, Ch.113, 1061-1072.

Finkelstein, A. (2010): Comment on "Mind the Gap! Consumer Perceptions and Choices of Medicare Part D Prescription Drug Plans.” In: D. A. Wise, ed., Research Findings in the Economics of Aging, Chicago and London: Chicago University Press, 481-484.

Guiso, L., and M. Paiella (2006): "The Role of Risk Aversion in Predicting Individual Behavior." In P. A. Chiappori and C. Gollier, ed., Insurance: Theoretical Analysis and Policy Implications, MIT Press. 
Halek, M., and J. G. Eisenhauer (2001): “Demography of Risk Aversion.” Journal of Risk and Insurance, 68(1), 1-24.

Hartog, J., A. Ferrer-I-Carbonell, and N. Jonkers (2002): "Linking Measured Risk Aversion to Individual Characteristics.” Kyklos, 55(1), 3-26.

Heiss, F., A. Leive, D. Mc Fadden, and J. Winter (2012): "Plan selection in Medicare Part D: Evidence from administrative data." Paper presented at the Annual Meeting of the American Economic Association, Chicago, IL.

Heiss, F., D. Mc Fadden, and J. Winter (2006): "Who Failed to Enroll in Medicare Part D, and Why? Early Results." Health Affairs, 2006, 25, w344-w354.

Heiss, F., D. Mc Fadden, and J. Winter (2010): "Mind the Gap! Consumer Perceptions and Choices of Medicare Part D Prescription Drug Plans.” In: D. A. Wise, ed., Research Findings in the Economics of Aging, Chicago and London: Chicago University Press, 413-481.

Heiss, F., D. McFadden, and J. Winter (2011): The demand for Medicare Part D prescription drug coverage: Evidence from four waves of the Retirement Perspectives Survey. In D.

A. Wise (Ed.), Explorations in the Economics of Aging, 159-182. Chicago and London: Chicago University Press.

Hershey, J. C., H. C. Kunreuther, and P. J. H. Schoemaker (1982): “Sources of Bias in Assessment Procedures for Utility Functions.” Management Science, 28(8), 936-954.

Holt, C. A., and S. K. Laury (2002): "Risk Aversion and Incentive Effects.” American Economic Review, 92(5), 1644-55.

Kahneman, D., and A. Tversky (1979): "Prospect Theory: An Analysis of Decision Under Risk.” Econometrica, 47, 263-291.

Ketcham, J. D., C. Lucarelli, E. J. Miravete, and M. C. Roebuck (2011): Sinking, swimming, or learning to swim in Medicare Part D. American Economic Review, forthcoming.

Kimball, M. S., C. R. Sahm, M. D. Shapiro (2008): "Imputing Risk Tolerance from Survey Response.” Journal of the American Statistical Association, 103(483), 1028-1038.

Kling, J. R., S. Mullainathan, E. Shafir, L. Vermeulen, and M. V. Wrobel (2011): Comparison friction: Experimental evidence from Medicare drug plans. Quarterly Journal of Economics, forthcoming.

Levy, H., and D. Weir (2010): "Take-up of Medicare Part D: Results from the Health and Retirement Study.” Journal of Gerontology: Social Sciences, 65B(4), 492-501. 
Picone, G., F. Sloan, and D. Taylor (2004): "Effects of Risk and Time Preference and Expected Longevity on Demand for Medical Tests.” Journal of Risk and Uncertainty, 28(1), 39-53.

Schubert, R., M. Brown, M. Gysler, and H. W. Brachinger (1999): "Financial DecisionMaking: Are Women Really More Risk-Averse?" AEA Papers and Proceedings, 89(2), 381-385.

Spinnewijn, J. (2009): "Insurance and Perceptions: How to Screen Optimists and Pessimists." mimeo.

Tversky, A., and D. Kahneman (1992): “Advances in Prospect Theory: Cumulative Representation of Uncertainty." Journal of Risk and Uncertainty, 5, 297-323.

Van der Pol, M., and M. Ruggeri (2008): "Is risk attitude specific within the health domain?" Journal of Health Economics, 27, 706-717.

Wakker, P. P., D. R. M. Timmermans, I. Machielse (2007): “The Effects of Statistical Information on Risk and Ambiguity Attitudes, and on Rational Insurance Decisions." Management Science, 53(11), 1770-1784.

Winter, J., R. Balza, F. Caro, F. Heiss, B.-H. Jun, R. Matzkin, and D. McFadden (2006): "Medicare Prescription Drug Coverage: Consumer Information and Preferences." Proceedings of the National Academy of Sciences of the United States of America, 103(20), 7929-7934. 
Figure 1: Distribution of answers to question A2

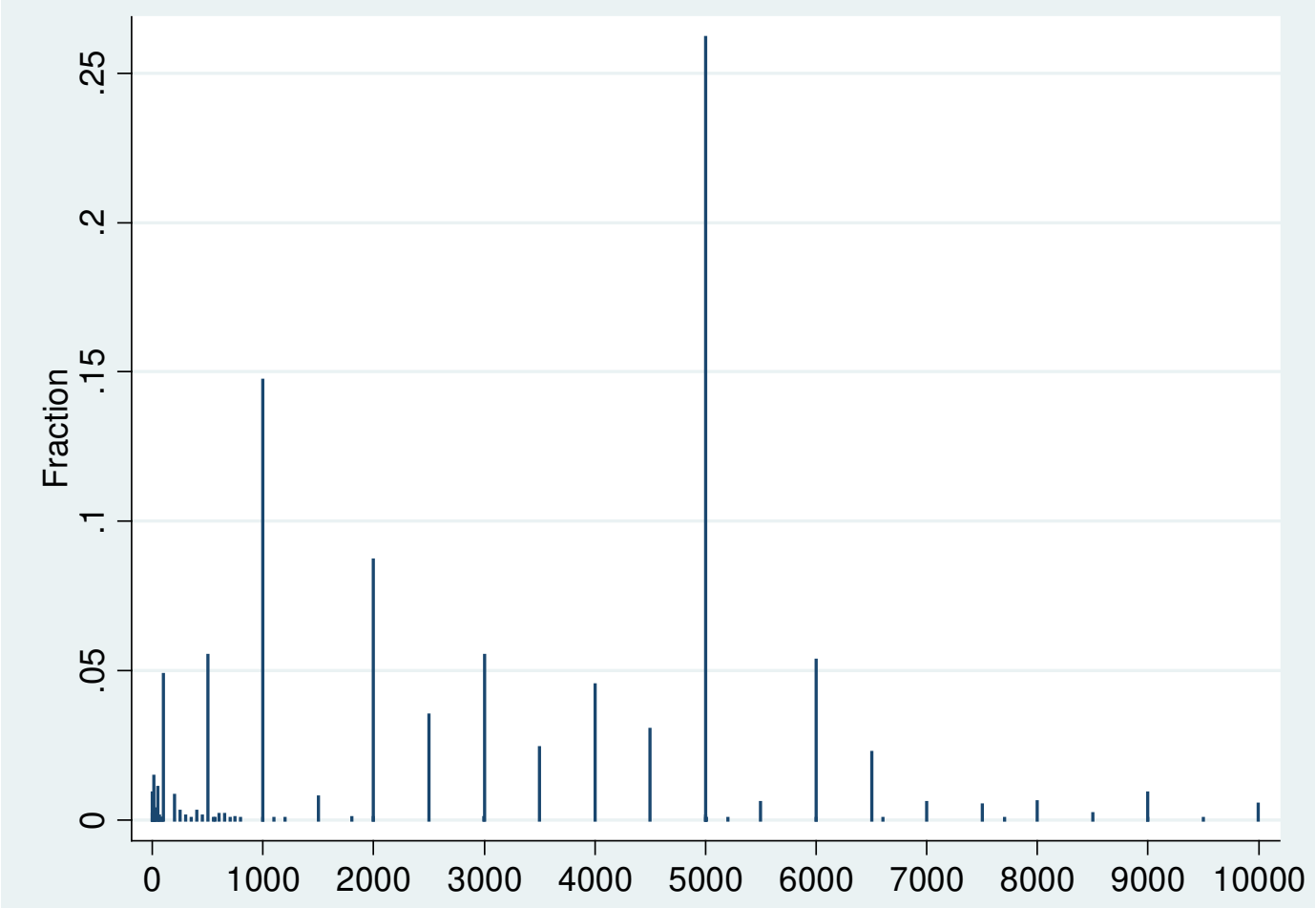

Figure 2: Distribution of answers to question B2 (truncated at 200)

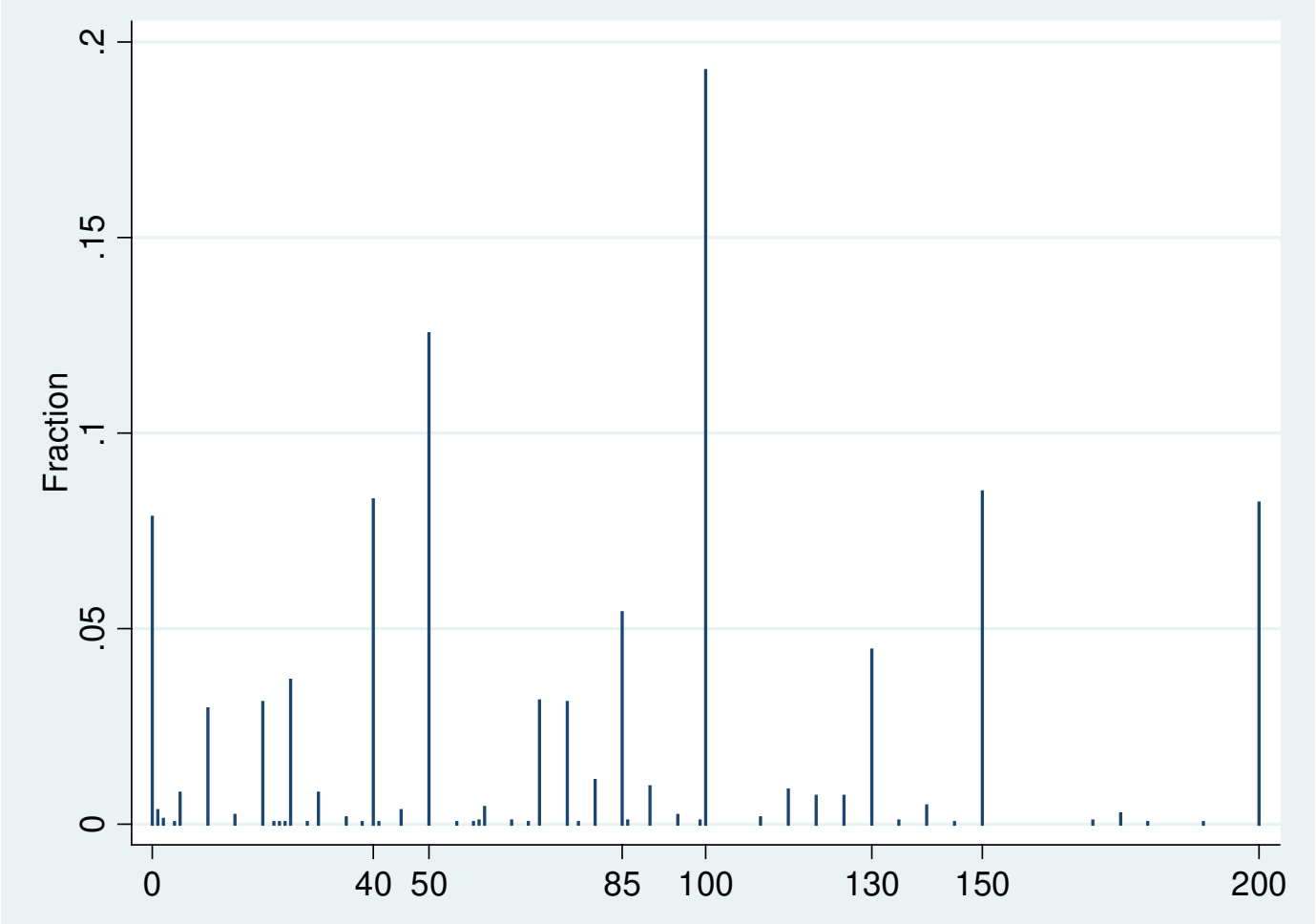


Figure 3: Answers to question A2 by brackets treatments

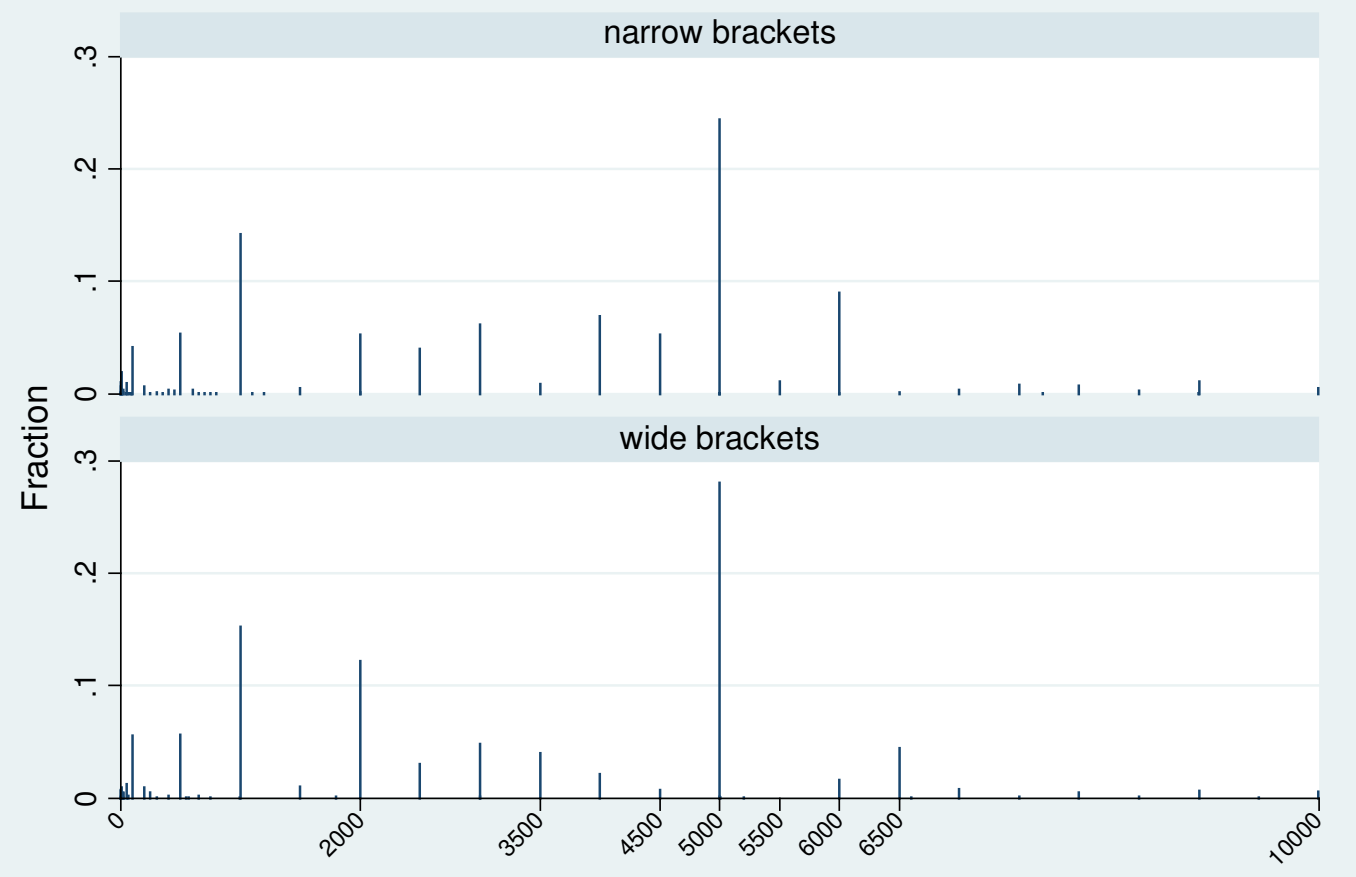

Figure 4: Cumulative distribution function for question A2

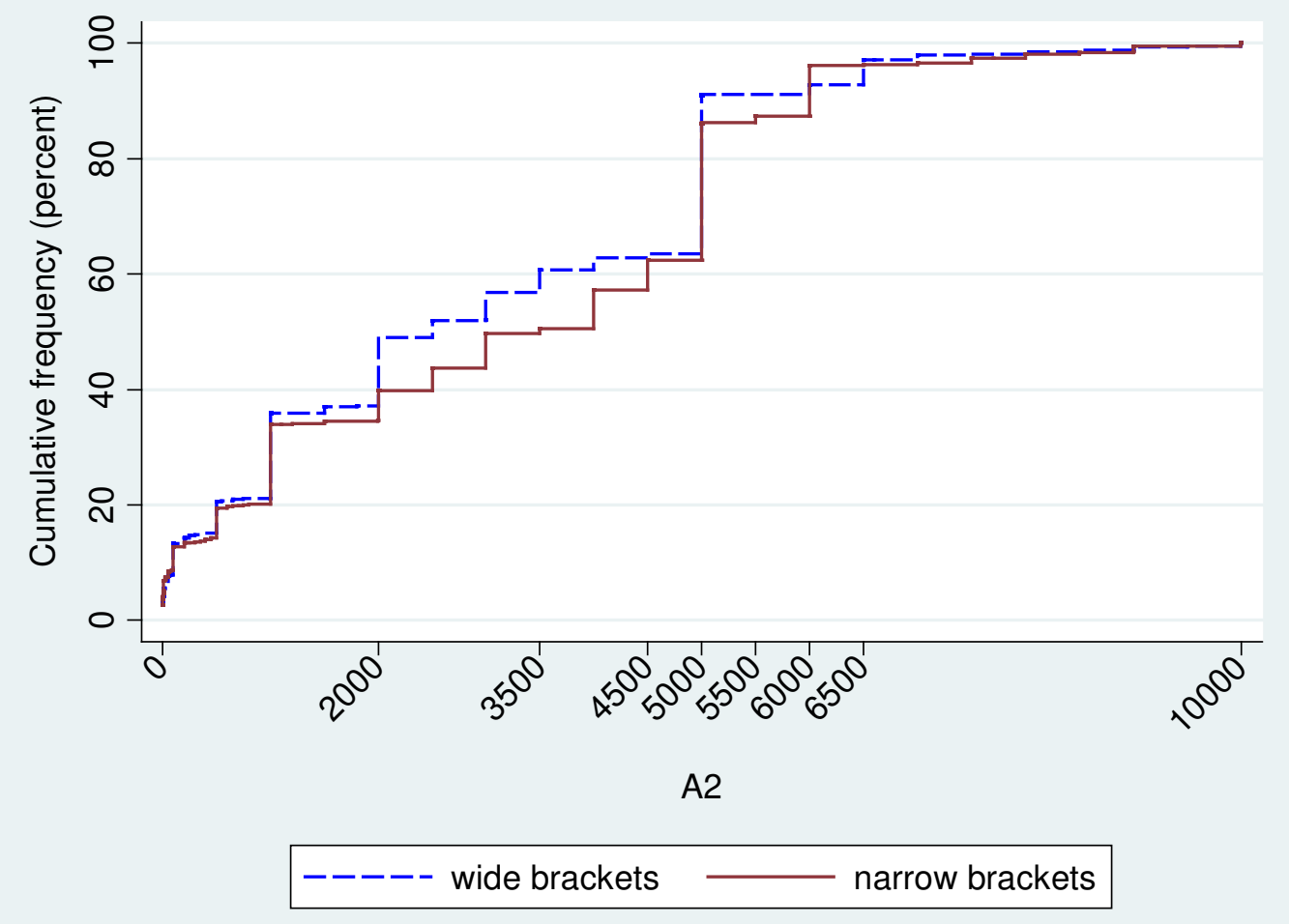

Two-sample Kolmogorov-Smirnov test for equality of distribution functions: p-value $<0.001$ 
Figure 5: Answers to question B2 by brackets treatments (truncated at 200)

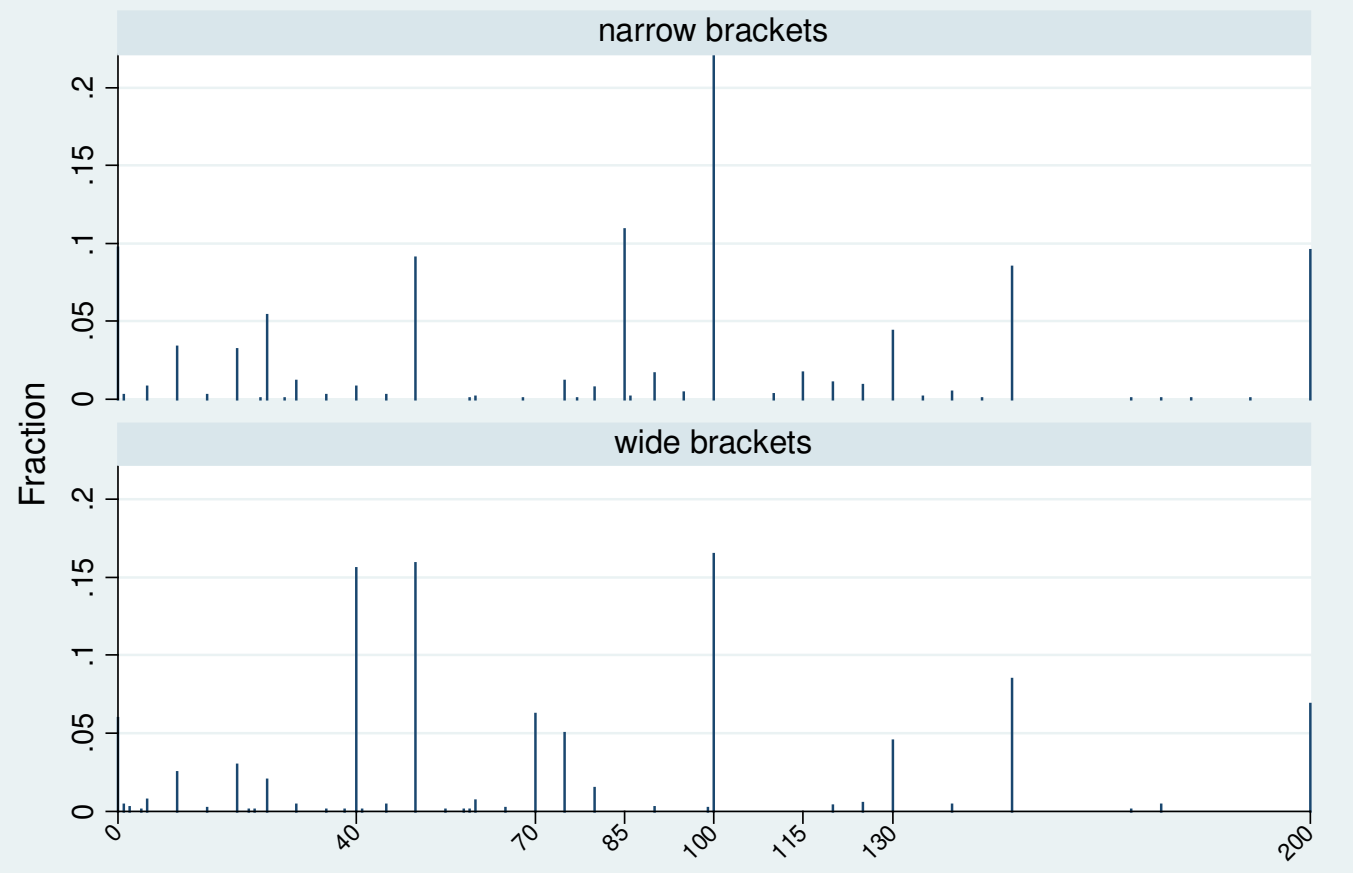

Figure 6: Cumulative distribution function for question B2 (truncated at 200)

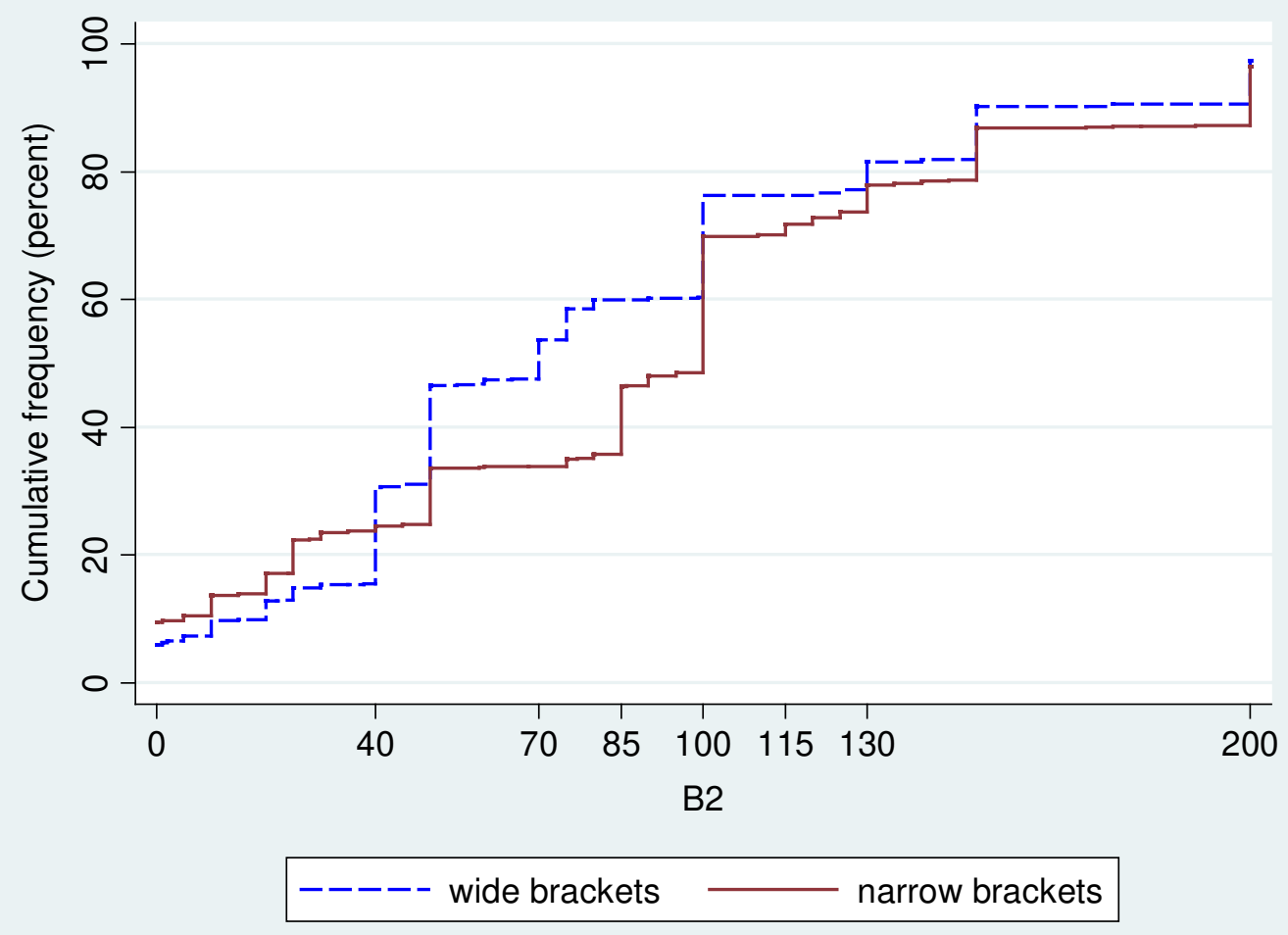

Two-sample Kolmogorov-Smirnov test for equality of distribution functions: p-value $<0.001$ 
Table 1: Treatment comparison of WTP and WTA questions

\section{A1: WTA for supermarket lottery}

Please indicate for each of these amounts whether you would take it for certain (rather than taking a fifty-fifty chance of getting $\$ 10,000$ or nothing):

\begin{tabular}{ccccc}
\hline & \multicolumn{2}{c}{ wide brackets } & \multicolumn{2}{c}{ narrow brackets } \\
$\$$ & NO & YES & NO & YES \\
\hline 6500 & $10.27 \%$ & $89.73 \%$ & & \\
6000 & & & $10.86 \%$ & $89.14 \%$ \\
5500 & & & $16.29 \%$ & $83.71 \%$ \\
5000 & $14.96 \%$ & $85.04 \%$ & $18.14 \%$ & $81.86 \%$ \\
4500 & & & $28.81 \%$ & $71.19 \%$ \\
3500 & $36.76 \%$ & $63.24 \%$ & & \\
2000 & $48.44 \%$ & $51.56 \%$ & &
\end{tabular}

B1: WTP for travel insurance

Please indicate below whether you would buy this insurance at various costs rather than taking a chance:

\begin{tabular}{ccccc}
\hline & \multicolumn{2}{c}{ wide brackets } & \multicolumn{2}{c}{ narrow brackets } \\
$\$$ & NO & YES & NO & YES \\
\hline 40 & $16.19 \%$ & $83.81 \%$ & & \\
70 & $41.90 \%$ & $58.10 \%$ & & \\
85 & & & $33.14 \%$ & $66.86 \%$ \\
100 & $60.73 \%$ & $39.27 \%$ & $50.17 \%$ & $49.83 \%$ \\
115 & & & $66.52 \%$ & $33.48 \%$ \\
130 & $72.34 \%$ & $27.66 \%$ & $69.84 \%$ & $30.16 \%$ \\
\hline
\end{tabular}


Table 2: Predictors of the risk aversion measures (OLS regressions)

\begin{tabular}{|c|c|c|c|c|}
\hline Dep. Variable: & $\begin{array}{l}\mathbf{( 1 )} \\
\mathrm{A} 2\end{array}$ & $\begin{array}{l}(2) \\
\alpha\end{array}$ & $\begin{array}{l}\text { (3) } \\
\text { B2 }\end{array}$ & $\begin{array}{r}(4) \\
\beta\end{array}$ \\
\hline constant & $\begin{array}{l}3179.2122 * * * \\
(132.2073)\end{array}$ & $\begin{array}{l}0.7468 * * * \\
(0.05322)\end{array}$ & $\begin{array}{l}103.8621 * * * \\
(6.6897)\end{array}$ & $\begin{array}{l}0.9592 * * * \\
(0.0236)\end{array}$ \\
\hline $\begin{array}{l}\text { A1 treatment } \\
\text { dummy }\end{array}$ & $\begin{array}{l}-281.6155^{* * * *} \\
(90.8509)\end{array}$ & $\begin{array}{l}-0.0732 * * \\
(0.0345)\end{array}$ & & \\
\hline $\begin{array}{l}\text { B1 treatment } \\
\text { dummy }\end{array}$ & & & $\begin{array}{l}-11.7355^{* *} \\
(4.6909)\end{array}$ & $\begin{array}{l}-0.0300^{*} \\
(0.0161)\end{array}$ \\
\hline age $>75$ & $\begin{array}{l}85.3777 \\
(102.9833)\end{array}$ & $\begin{array}{l}0.0318 \\
(0.0402)\end{array}$ & $\begin{array}{l}-2.4164 \\
(5.2935)\end{array}$ & $\begin{array}{l}-0.0081 \\
(0.0193)\end{array}$ \\
\hline $\begin{array}{l}\text { education below } \\
\text { highschool level }\end{array}$ & $\begin{array}{l}-101.076 \\
(95.4555)\end{array}$ & $\begin{array}{l}-0.0220 \\
(0.0356)\end{array}$ & $\begin{array}{l}-12.9473 * * * \\
(4.9274)\end{array}$ & $\begin{array}{l}-0.0421 * * * \\
(0.0157)\end{array}$ \\
\hline male & $\begin{array}{l}-41.6113 \\
(91.2655)\end{array}$ & $\begin{array}{l}0.0013 \\
(0.0345)\end{array}$ & $\begin{array}{l}-2.3736 \\
(4.7179)\end{array}$ & $\begin{array}{l}-0.0012 \\
(0.0165)\end{array}$ \\
\hline $\begin{array}{l}\text { household } \\
\text { income }<\$ 30,000\end{array}$ & $\begin{array}{l}-34.7375 \\
(110.6319)\end{array}$ & $\begin{array}{l}0.0207 \\
(0.0401)\end{array}$ & $\begin{array}{l}-4.8590 \\
(5.7066)\end{array}$ & $\begin{array}{l}-0.0150 \\
(0.0192)\end{array}$ \\
\hline $\begin{array}{l}\text { household } \\
\text { income }>\$ 60,000\end{array}$ & $\begin{array}{l}177.6066 \\
(122.3170)\end{array}$ & $\begin{array}{l}0.0529 \\
(0.0469)\end{array}$ & $\begin{array}{l}4.3549 \\
(6.3902)\end{array}$ & $\begin{array}{l}0.0291 \\
(0.0205)\end{array}$ \\
\hline nonwhite & $\begin{array}{l}145.6331 \\
(129.7351)\end{array}$ & $\begin{array}{l}0.0574 \\
(0.0497)\end{array}$ & $\begin{array}{l}18.5246 * * * \\
(6.4311)\end{array}$ & $\begin{array}{l}0.0580 * * \\
(0.0277)\end{array}$ \\
\hline SAH excellent & $\begin{array}{l}152.2851 \\
(191.4282)\end{array}$ & $\begin{array}{l}0.0593 \\
(0.0773)\end{array}$ & $\begin{array}{l}-4.1146 \\
(9.9175)\end{array}$ & $\begin{array}{l}-0.0138 \\
(0.0291)\end{array}$ \\
\hline SAH (very) poor & $\begin{array}{l}24.6384 \\
(105.6686)\end{array}$ & $\begin{array}{l}0.0348 \\
(0.0409)\end{array}$ & $\begin{array}{l}10.1463 * \\
(5.4042)\end{array}$ & $\begin{array}{l}0.0405 \\
(0.0197)\end{array}$ \\
\hline $\mathbf{N}$ & 2541 & 2541 & 2526 & 2526 \\
\hline $\mathbf{R 2}$ & 0.0073 & 0.0039 & 0.0124 & 0.0116 \\
\hline $\mathbf{F}$ & 2.2303 & 1.3728 & 3.5012 & 3.5764 \\
\hline Log-likelihood & $-2.325 e+04$ & -3224.4427 & $-1.562 \mathrm{e}+04$ & -1862.3003 \\
\hline
\end{tabular}

Notes: Respondents with B2>=2000 were dropped. Heteroscedasticity robust standard errors in parentheses; * $\mathrm{p}<0.10, * * \mathrm{p}<0.05, * * * \mathrm{p}<0.01$ 
Table 3: Predictors of Part D enrollment (probit regressions)

\begin{tabular}{|c|c|c|c|c|c|c|}
\hline & \multicolumn{4}{|c|}{ Full sample } & \multirow{2}{*}{$\begin{array}{c}\text { B1 narrow } \\
\text { brackets }\end{array}$} & \multirow{2}{*}{$\begin{array}{c}\text { B1 wide } \\
\text { bracket } \\
\text { (6) }\end{array}$} \\
\hline & (1) & (2) & (3) & (4) & & \\
\hline \multirow[t]{2}{*}{ constant } & $0.5054 * *$ & 0.3821 & -0.2671 & -0.4315 & -0.0609 & $-0.7694 *$ \\
\hline & $(0.1969)$ & $(0.2203)$ & $(0.3251)$ & $(0.3438)$ & $(0.4972)$ & $(0.4370)$ \\
\hline \multirow[t]{2}{*}{$\alpha$} & & 0.0697 & & 0.0893 & & \\
\hline & & $(0.0903)$ & & $(0.0953)$ & & \\
\hline \multirow{2}{*}{$\begin{array}{l}\text { A1 treatment } \\
\text { dummy }\end{array}$} & & 0.1495 & & 0.1572 & & \\
\hline & & $(0.1492)$ & & $(0.1514)$ & & \\
\hline \multirow[t]{2}{*}{$\beta$} & & & $0.8092 * * *$ & $0.8366^{* * * *}$ & 0.4412 & $1.2542 * * *$ \\
\hline & & & $(0.2967)$ & $(0.2967)$ & $(0.4416)$ & $(0.4200)$ \\
\hline \multirow{2}{*}{$\begin{array}{l}\text { B1 treatment } \\
\text { dummy }\end{array}$} & & & 0.0865 & 0.0883 & & \\
\hline & & & $(0.1506)$ & $(0.1511)$ & & \\
\hline \multirow{2}{*}{$\begin{array}{l}\text { prescription drug } \\
\text { expenditure in } \$\end{array}$} & $0.0032 * *$ & $0.0032 * *$ & $0.0032 * * *$ & $0.0032 * * *$ & $0.0051 * * *$ & $0.0028 * *$ \\
\hline & $(0.0013)$ & $(0.0013)$ & $(0.0012)$ & $(0.0011)$ & $(0.0017)$ & $(0.0014)$ \\
\hline \multirow{2}{*}{$\begin{array}{l}\text { other medical } \\
\text { insurance }\end{array}$} & $0.6944 * * *$ & $0.6891 * * *$ & $0.6980^{* * *}$ & $0.6942 * * *$ & 0.3241 & $1.1428^{* * *}$ \\
\hline & $(0.1716)$ & $(0.1717)$ & $(0.1735)$ & $(0.1741)$ & $(0.2393)$ & $(0.2739)$ \\
\hline \multirow[t]{2}{*}{ SAH excellent } & $-0.8050 * * *$ & $-0.8047 * * *$ & $-0.8075 * * *$ & $-0.8095 * * *$ & $-1.3441 * * *$ & -0.2465 \\
\hline & $(0.2392)$ & $(0.2402)$ & $(0.2427)$ & $(0.2447)$ & $(0.3952)$ & $(0.3639)$ \\
\hline \multirow[t]{2}{*}{ SAH (very) poor } & -0.1719 & -0.1588 & -0.1887 & -0.1737 & 0.0306 & $-0.5333^{*}$ \\
\hline & $(0.2029)$ & $(0.2014)$ & $(0.2036)$ & $(0.2021)$ & $(0.2966)$ & $(0.3007)$ \\
\hline \multirow[t]{2}{*}{ age $>75$} & 0.1897 & 0.1887 & 0.1895 & 0.1876 & 0.1747 & $0.4180^{*}$ \\
\hline & $(0.1547)$ & $(0.1552)$ & $(0.1579)$ & $(0.1585)$ & $(0.2171)$ & $(0.2506)$ \\
\hline \multirow{2}{*}{$\begin{array}{l}\text { education below } \\
\text { highschool level }\end{array}$} & -0.2205 & -0.2122 & -0.2198 & -0.2106 & -0.1970 & -0.0958 \\
\hline & $(0.1511)$ & $(0.1504)$ & $(0.1541)$ & $(0.1539)$ & $(0.2156)$ & $(0.2352)$ \\
\hline \multirow[t]{2}{*}{ male } & 0.0760 & 0.0636 & 0.1111 & 0.1009 & $0.4780 * *$ & -0.0814 \\
\hline & $(0.1530)$ & $(0.1532)$ & $(0.1544)$ & $(0.1547)$ & $(0.2195)$ & $(0.2291)$ \\
\hline household income & -0.0703 & -0.0696 & -0.0617 & -0.0636 & -0.0485 & 0.0307 \\
\hline$<\$ 30,000$ & $(0.1699)$ & $(0.1694)$ & $(0.1719)$ & $(0.1719)$ & $(0.2454)$ & $(0.2624)$ \\
\hline household income & 0.2873 & 0.2930 & 0.2408 & 0.2434 & 0.3268 & 0.3215 \\
\hline$>\$ 60,000$ & $(0.2257)$ & $(0.2290)$ & $(0.2291)$ & $(0.2329)$ & $(0.3174)$ & $(0.3206)$ \\
\hline \multirow[t]{2}{*}{ nonwhite } & 0.2967 & 0.2652 & 0.2642 & 0.2199 & 0.3014 & 0.1949 \\
\hline & $(0.2675)$ & $(0.2678)$ & $(0.2691)$ & $(0.2660)$ & $(0.3714)$ & $(0.3936)$ \\
\hline $\mathbf{N}$ & 407 & 407 & 407 & 407 & 209 & 198 \\
\hline Pseudo-R ${ }^{2}$ & 0.1282 & 0.1316 & 0.1466 & 0.1509 & 0.1962 & 0.1924 \\
\hline $\begin{array}{l}\text { Log- } \\
\text { pseudolikelihood }\end{array}$ & -187.467 & -186.724 & -183.506 & -182.576 & -92.434 & -80.461 \\
\hline
\end{tabular}

Notes: Dependent variable $=1$ if respondent enrolled in Part D, 0 otherwise. Respondents with B2 $>=2000$ were dropped. Heteroscedasticity robust standard errors in parentheses; * $\mathrm{p}<0.10, * * \mathrm{p}<0.05$, $* * * \mathrm{p}<0.01$. 


\section{Appendix A: Questionnaire section on risk preferences}

\section{Question A1:}

Suppose your supermarket announces that in a drawing from its customers you are the winner of the grand prize. This prize gives you a fifty-fifty chance of getting $\$ 10,000$ or getting nothing. Alternately, you may choose an amount for certain rather than taking a chance of getting nothing.

Please indicate for each of these amounts whether you would take it for certain (rather than taking a fifty-fifty chance of getting $\$ 10,000$ or nothing):

\section{Wide brackets treatment:}

\begin{tabular}{|l|c|c|}
\hline & No & Yes \\
\hline$\$ 6,500$ & $\square$ & $\square$ \\
\hline$\$ 5,000$ & $\square$ & $\square$ \\
\hline$\$ 3,500$ & $\square$ & $\square$ \\
\hline$\$ 2,000$ & $\square$ & $\square$ \\
\hline
\end{tabular}

\section{Narrow brackets treatment:}

\begin{tabular}{|l|c|c|}
\hline & No & Yes \\
\hline$\$ 6 \mathbf{6 , 0 0 0}$ & $\square$ & $\square$ \\
\hline$\$ 55,500$ & $\square$ & $\square$ \\
\hline$\$ 5,000$ & $\square$ & $\square$ \\
\hline$\$ 4,500$ & $\square$ & $\square$ \\
\hline
\end{tabular}

\section{Question A2:}

Still thinking about the super market prize that gives you a fifty-fifty chance of getting $\$ 10,000$ or getting nothing, as just described. What is the minimum amount you would choose for certain?

Please enter the dollar amount here: \$ 


\section{Question B1:}

Suppose you are planning a vacation that costs $\$ 2,000$ up front. There is a five percent chance that something will come up, and you will be unable to go. Your travel agent offers you insurance that will refund your $\$ 2,000$ if you can't go.

Please indicate below whether you would buy this insurance at various costs rather than taking a chance:

\section{Narrow brackets treatment:}

\begin{tabular}{|l|c|c|}
\hline & No & Yes \\
\hline$\$ 85$ & $\square$ & $\square$ \\
\hline$\$ 100$ & $\square$ & $\square$ \\
\hline$\$ 115$ & $\square$ & $\square$ \\
\hline
\end{tabular}

Wide brackets treatment:

\begin{tabular}{|l|c|c|}
\hline & No & Yes \\
\hline$\$ 40$ & $\square$ & $\square$ \\
\hline$\$ 70$ & $\square$ & $\square$ \\
\hline$\$ 100$ & $\square$ & $\square$ \\
\hline$\$ 130$ & $\square$ & $\square$ \\
\hline
\end{tabular}

\section{Question B2}

Still thinking about a vacation that costs $\$ 2,000$ up front and assuming there is a five percent chance that you will be unable to go. What is the maximum amount you would pay for insurance that would refund the cost, as just described?

Please enter the dollar amount here: \$ 